\title{
Arguments for an age-adapted definition of chronic kidney disease
}

\author{
Pierre Delanaye ${ }^{1,2}$ iD, Etienne Cavalier ${ }^{3}$ iD \\ ${ }^{1}$ Department of Nephrology-Dialysis-Transplantation, University of Liège, CHU Sart Tilman, Liège, Belgium \\ 2 Department of Nephrology-Dialysis-Apheresis, Hôpital Universitaire Carémeau, Nîmes, France \\ ${ }^{3}$ Department of Clinical Chemistry, University of Liège, CHU Sart Tilman, Liège, Belgium
}

Defining a disease or a pathological status is not easy. For many pauci-symptomatic diseases, biological results are of outstanding importance. Most clinicians are scarcely aware how much laboratories have to do to establish such reference or "normal" values. Laboratories have to follow different complex procedures ${ }^{1}$. In the same vein, laboratory specialists well know that every biological result given to the clinicians is vitiated by an inevitable error, known as the measurement uncertainty ${ }^{2}$. On the other hand, clinicians too often consider laboratory results as Gospel words carved in stone. The current definition of chronic kidney disease (CKD) is no exception. Indeed, Kidney Disease: Improving Global Outcomes (KDIGO) guidelines are recommending that all subjects with estimated glomerular filtration rate eGFR below $60 \mathrm{~mL} / \mathrm{min} / 1.73 \mathrm{~m}^{2}$ should be considered as a CKD patient ${ }^{3}$. The drawbacks arising from the use of fixed thresholds must be considered. An estimation of $59 \mathrm{~mL} / \mathrm{min} / 1.73 \mathrm{~m}^{2}$ will be too frequently considered as CKD, whereas a not-so-different value of $61 \mathrm{~mL} / \mathrm{min} / 1.73 \mathrm{~m}^{2}$ will not. Only the uncertainty measurement surrounding the analytical determination of creatinine could be enough to argue that these two values are actually not different (because sex and gender, the other variables in eGFR equations, are quite solid variables, most of the time). To help in the interpretation of an eGFR result, it is important to underline that the KDIGO also recommend that a low eGFR value must be confirmed at three months. This recommendation is important, and often neglected in epidemiological studies, to exclude patients with acute kidney injury, but repeating the measurement also helps to better diagnose these patients with an eGFR at the limit of the threshold 4 .

Beyond the inherent uncertainty of any biological measurement, one must bear in mind that, regarding a CKD diagnosis, an estimation, eGFR, with an equation is considered. And this estimation can be of low precision. An eGFR equation is considered as accurate when the relative difference with measured GFR is within $30 \%$. This means that, for a threshold at $60 \mathrm{~mL} / \mathrm{min} / 1.73 \mathrm{~m}^{2}$, a value of 42 or $78 \mathrm{~mL}$ / $\mathrm{min} / 1.73 \mathrm{~m}^{2}$ will be considered as accurate! Recent data have well illustrated that estimating GFR failed to correctly stage the subjects over or under $60 \mathrm{~mL} / \mathrm{min} / 1.73 \mathrm{~m}^{2}$ in a very large proportion. Around 40 to $50 \%$ of estimated results fail to classify the subject in the same KDIGO stage as the measured GFR. More importantly, around $10 \%$ of subjects will be classified with an error of two stages compared to measured GFR ${ }^{5,6}$.

The choice of a fixed threshold of $60 \mathrm{~mL} / \mathrm{min} / 1.73 \mathrm{~m}^{2}$ has the advantage of simplicity. That is undeniable. However, beyond the limitations inherent in any threshold, the choice of a fixed threshold for CKD definition has other specific limitations that might be strongly challenged. The first is the very well-known normal physiological decline in GFR with aging. Several studies have shown that after 40 years, GFR declines with aging. This means that a large proportion (up to $25 \%$ ) of healthy subjects over 75 years of age could be diagnosed as having CKD. Importantly, this decline in GFR has been illustrated with measured GFR and with estimating GFR (using different equations) in the world's population. Percentiles of eGFR or measured GFR do thus exist and are available for clinical use $^{3,7,8}$. One main argument of the KDIGO for keeping the fixed GFR threshold at $60 \mathrm{~mL} / \mathrm{min} / 1.73 \mathrm{~m}^{2}$ is an epidemiolocal one. Many large-scale studies from the Chronic Kidney Disease epidemiology (CKD-EPI) consortium have claimed that mortality was significantly higher in general or high-risk populations when eGFR was below 60 $\mathrm{mL} / \mathrm{min} / 1.73 \mathrm{~m}^{2}$, whatever the age considered ${ }^{9}$. However, all these epidemiological studies shared the same limitation, as they have a control group with an eGFR around $90 \mathrm{~mL} / \mathrm{min} / 1.73 \mathrm{~m}^{2}$. An analysis of the same database according to age categories showed that a different group control should be considered according to age. Indeed, the "normal" GFR range, corresponding to the GFR associated with the lowest mortality rate, is observed in higher GFR ranges in young people than in old populations. Calculation of risk with such a methodology confirm that a higher mortality risk is observed when eGFR is below $45 \mathrm{ml} / \mathrm{min} / 1.73 \mathrm{~m}^{2}$ in subjects older than 65 years; below $60 \mathrm{ml} / \mathrm{min} / 1.73 \mathrm{~m}^{2}$ in subjects between 40 and 65 years, and below $75 \mathrm{ml} / \mathrm{min} / 1.73 \mathrm{~m}^{2}$ in subjects younger than 40 years ${ }^{3}$. Several authors claim for an age-adapted CKD definition ${ }^{3,10}$. Using GFR percentiles is the best scientific solution for such an age-adapted definition. Using percentiles is less impacted by the measurement uncertainty. Percentiles are also very useful for early detection of a "brake" in the slope of GFR of a given patient (even if the GFR value is in the normal range). Percentiles could potentially help in the detection of hyperfiltration. It is important to note that such percentiles are useful in the early detection of CKD in young subjects, as the threshold at $60 \mathrm{~mL} / \mathrm{min} / 1.73 \mathrm{~m}^{2}$ seems totally unsuitable and much too low in this specific population ${ }^{3,11}$. At the population level, the use of such percentiles will profoundly impact the epidemiology of CKD, with a large decrease of CKD prevalence (up to 30 to 50\%) in elderly populations, but an increase of CKD prevalence in young populations. However, the impact of this increase prevalence in young populations will have a limited impact on the global crude CKD prevalence because, hopefully, the prevalence of CKD in young people is low ${ }^{12,13}$.

In this perspectives article, we focused on GFR and its interpretation. We must keep in mind that there is another key parameter, namely the measurement of urine albumin-to-creatinine ratio (ACR), for the diagnosis of ACR. Interpretation of ACR has its own caveats, but it remains very important to measure ACR in patients at risk. As 
an example, ACR is still too frequently forgotten in diabetic patients, whereas the presence of abnormal albuminuria level is enough for a CKD diagnosis, whatever the GFR level.

Interpretation of GFR percentiles is thus easy and can help the nephrologists in many situations ${ }^{11}$. The results of percentiles must ideally be interpreted with an ACR result to establish the renal risk and propose a dedicated therapy ${ }^{11}$.

\section{Acknowledgments}

The authors are members of the European Kidney Function Consortium (EKFC).

Disclosure of potential conflicts of interest: none declared.

\section{References}

1. Cavalier E, Delanaye P. Defining a "reference population": no easy task. J Bone Miner Res 2009; 24: 1638.

2. Cavalier E, Ferir A-MAMA-M, Delanaye P, Krzesinski J-MJMJ-M, Chapelle JPJ-P. Measurement uncertainty of creatinine in low values: Another good reason not to use the MDRD formula with low creatinine values. Clin Biochem 2007; 40: 285-286.

3. Delanaye $\mathrm{P}$, Jager KJ, Bökenkamp A et al. CKD: A call for an age-adapted definition. J Am Soc Nephrol 2019; 30: 1785-1805.

4. Benghanem Gharbi M, Elseviers M, Zamd M et al. Chronic kidney disease, hypertension, diabetes, and obesity in the adult population of Morocco: how to avoid "over"- and "under"-diagnosis of CKD. Kidney Int 2016; 89: 1363-1371.
5. Delanaye P, Björk J, Courbebaisse M et al. Performance of creatinine-based equations to estimate glomerular filtration rate with a methodology adapted to the context of drug dosage adjustment. Br J Clin Pharmacol 2021; Epub ahead of print.

6. Luis-Lima S, Escamilla-Cabrera B, Negrín-Mena $N$ et al. CKD staging with cystatin C or creatinine-based formulas: flipping the coin. Nephrol Dial Transplant 2019; 34: 287-294.

7. Yayo $\mathrm{E}, \mathrm{Ayé} \mathrm{M}, \mathrm{Yao} \mathrm{C}$ et al. Measured (and estimated) glomerular filtration rate: reference values in West Africa. Nephrol Dial Transplant 2018; 33: 1176-1180.

8. Delanaye P, Gaillard F, Van Der Weijden J et al. Age-adapted percentiles of measured glomerular filtration in healthy individuals: Extrapolation to living kidney donors over 65 years. Clin Chem Lab Med 2021; Epub ahead of print.

9. Hallan $\mathrm{SI}$, Matsushita K, Sang Y et al. Age and association of kidney measures with mortality and end-stage renal disease. JAMA 2012; 308: 2349.

10. Denic A, Glassock RJ, Rule AD. Structural and functional changes with the aging kidney. Adv Chronic Kidney Dis 2016; 23: 19-28.

11. Luyckx VA, Rule AD, Tuttle KR et al. Nephron overload as a therapeutic target to maximize kidney lifespan. Nat Rev Nephrol 2022; Epub ahead of print.

12. De Broe ME, Gharbi MB, Zamd M, Elseviers M. Why overestimate or underestimate chronic kidney disease when correct estimation is possible? Nephrol Dial Transplant 2017; 32: ii136-ii141.

13. Jonsson AJ, Lund SH, Eriksen BO, Palsson R, Indridason OS. The prevalence of chronic kidney disease in Iceland according to KDIGO criteria and age-adapted estimated glomerular filtration rate thresholds. Kidney Int 2020; 98: 1286-1295.

\section{ORCID}

Pierre Delanaye (iD) 0000-0002-1480-5761

Etienne Cavalier (iD 0000-0003-0947-2226

\section{Correspondence to:}

Pierre Delanaye, MD

Service de Dialyse, CHU Sart Tilman, 4000 Liège, Belgium.

Email: pierre_delanaye@yahoo.fr

C 2021 Portuguese Journal of Nephrology \& Hypertension. Published by Publicações Ciência \& Vida This is an open access article under the CC BY-NC-ND license (http://creativecommons.org/licenses/by-nc-nd/4.0/). 